\title{
Pattern recognition of structural boundaries from aeromagnetic data using the 2-D continuous wavelet transform and the 3-D analytic signal
}

\author{
S.-A. Ouadfeul ${ }^{1}$ and L. Aliouane ${ }^{2,3}$ \\ ${ }^{1}$ Geosciences and Mines, Algerian Petroleum Institute, IAP, Boumerdes, Algeria \\ ${ }^{2}$ Geophysics department, FSTGAT, USTHB, Algiers, Algeria \\ ${ }^{3}$ LABOPHYT, FHC, UMBB, Boumerdes, Algeria \\ Correspondence to: S.-A. Ouadfeul (souadfeul@ymail.com)
}

Received: 5 January 2013 - Revised: 19 February 2013 - Accepted: 20 February 2013 - Published: 5 March 2013

\begin{abstract}
The main goal of this paper is to use the 2-D continuous wavelet transform (CWT) combined with the 3-D analytic signal (AS) for structural boundaries delimitation from aeromagnetic data. The basic idea is based on the mapping of the maxima of the modulus of the 2-D CWT of the amplitude of the 3-D analytic signal (AS) for the full range of scales used to calculate the 2-D CWT. The proposed idea is applied to the synthetic data of a prism and a cylinder; obtained results show the power of this technique for contacts mapping in cases of high vector magnetization direction. Obtained results of the application to real aeromagnetic data of In Ouzzal area located in the west of Hoggar (Algeria) are compared with the 3-D analytic signal solutions. They show robustness of the proposed tool for pattern recognition of structural boundaries from potential geomagnetic data.
\end{abstract}

\section{Introduction}

The wavelet transform has been widely used for potential gravity and magnetic data analysis in the last decade, with the goal to provide a model of causative sources; one use of such a model is to predict a pattern of geological boundaries.

Ouadfeul et al. (2012) and Ouadfeul and Aliouane (2012a, b) have published papers on the structural boundaries delimitation from gravity and magnetic data using a type of directional continuous wavelet transform introduced by Murenzi (1989). Ouadfeul et al. (2012) have demonstrated that the directional continuous wavelet transform requires a reduction to the pole (RTP) for better causative sources characterization and it is very sensitive to noise. The RTP requires the knowledge of the magnetic Inclination $(I)$ and Declination $(D)$.

These angles are not easy in terms of finding cases of high magnetic remanence, it requires pertrophysical measurement at the laboratory, which is expensive. Here, we propose a technique of structural boundaries delimitation from aeromagnetic data based on the analysis of the 3-D analytic signal which not requires a reduction to the pole (Ansari and Alamdar, 2009) by the continuous wavelet transform.

We start the paper with an introduction, after which we describe the flow chart of the proposed idea and then apply the technique to a synthetic model of cylinder and prism. The technique is then applied to the real aeromagnetic data of In Ouzzal area, located in Hoggar (Algeria); we finalize the paper by results interpretation and a conclusion

\section{The 2-D continuous wavelet transform}

The 2-D continuous wavelet transform of a signal $S(x, y)$ is defined as a decomposition of $S$ on translated and dilated version of a mother wavelet $\psi(x, y)$. The 2-D CWT coefficients are given by (Murenzi, 1989):

$C_{s}\left(b_{1}, b_{2}, a\right)=\iint_{R^{2}} S(x, y) \overline{\psi\left(\frac{x-b_{1}}{a}, \frac{y-b_{2}}{a}\right)} \mathrm{d} x \mathrm{~d} y$

where $b_{1}, b_{2}$ are the translations in the space. $a$ is the scale; $a>0, \bar{\psi}$ is the complex conjugate of $\psi, \psi(x, y)$, which must 
Calculation of amplitude of the 3D analytic signal (AS) of the potential magnetic field $\mathrm{F}$

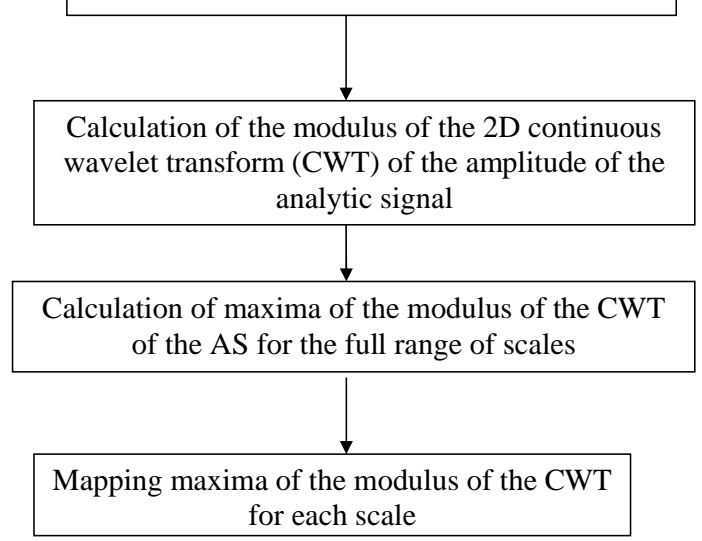

Figure 1. Flow chart of the potential field analysis using the 3-D AS and 2-D CWT.

check the admissibility condition

$\iint_{R^{2}} \psi(x, y) \mathrm{d} x \mathrm{~d} y=0$.

For some requirements, $\psi(x, y)$ must have $N$ vanishing moments; it means $\psi(x, y)$ must be orthogonal to any polynomial of $N-1$ degree:

$$
\iint_{R^{2}} \psi(x, y) P_{N-1}(x, y) \mathrm{d} x \mathrm{~d} y=0
$$

There are many examples of analyzing wavelet in geophysics; a special interest was given to the so called Poisson's Kernel wavelet defined by Fedi and Cascone (2008):

$\psi(x, y)=\frac{1}{2 \Pi} \frac{1}{\left[x^{2}+y^{2}+1\right]^{3 / 2}}$.

This interest originated in the analogy between the upward continuation and the wavelet transform (Fedi and Cascone, 2008; Ouadfeul et al., 2010). The modulus of the CWT of a potential field $F(x, y)$ with the Poisson kernel as analyzing wavelet is equivalent to the same field upwarded to a level $Z=a$ (Ouadfeul et al., 2012).

In this paper, we will analyze the amplitude of the 3-D analytic signal by the 2-D continuous wavelet transform with the cited analyzing wavelet for the purpose of providing a structural boundaries pattern from aeromagnetic data. Let us give a notion of the $3-\mathrm{D}$ analytic signal.

\section{Analytic signal}

Nabighian $(1972,1984)$ developed the notion of 2-D analytic signal, or energy envelope, of magnetic anomalies. Roest et
Table 1a. Physical parameters of the cylinder.

\begin{tabular}{ll}
\hline Coordinates of the center & $(5000,2500,-250)$ \\
\hline Ray & $1500 \mathrm{~m}$ \\
High & $2500 \mathrm{~m}$ \\
Magnetic susceptibility & $K=0.015 \mathrm{SI}$ \\
$F$ & $37000 \mathrm{nT}$ \\
Declination & $D=30^{\circ}$ \\
Inclination & $I=60 \circ$ \\
\hline
\end{tabular}

al. (1992) showed that the amplitude (absolute value) of the 3-D analytic signal at location $(x, y)$ can be easily derived from the three orthogonal gradients of the total magnetic field using the following expression (Roest et al, 1992):

$|A(x)|=\sqrt{\left(\frac{\partial F}{\partial x}\right)^{2}+\left(\frac{\partial F}{\partial y}\right)^{2}+\left(\frac{\partial F}{\partial z}\right)^{2}}$

where $|A(x, y)|$ is the amplitude of the analytic signal at $(x, y)$. $F$ is the intensity of the observed magnetic field at $(x, y)$.

An important comment at this point is that the analytic signal can be easily calculated. The $x$ and $y$ derivatives can be calculated directly from a total magnetic field grid using a simple $3 \times 3$ filter, and the vertical gradient is routinely calculated using FFT techniques. The analytic signal anomaly over a 2-D magnetic contact located at $(x=0)$ and at depth $h$ is described by the following expression from Nabighian (1972):

$|A(x)|=\alpha \frac{1}{\left(h^{2}+x^{2}\right)^{0.5}}$

where $\alpha$ is the amplitude factor $\alpha=2 M \sin (d)\left(1-\cos (I)^{2}\right.$ $\left.\sin (A)^{2}\right)$ ), and $h$ is the depth to the top of the contact. $M$ is the strength of magnetization, $d$ is the dip of the contact, $I$ is the inclination of the magnetization vector, and $A$ is the direction of the magnetization vector.

\section{The processing algorithm}

The proposed idea is based at the mapping of maxima of the modulus of the 2-D continuous wavelet transform of the amplitude of the analytic signal for each scale used in the calculation of the 2-D CWT. Figure 1 shows a detailed flow chart of this technique.

\section{Application to synthetic data}

To check the efficiency of the proposed technique to detect structural boundaries in cases of high remanence and noisy geomagnetic data, we have generated a geomagnetic response of a synthetic model of a cylinder and a prism. Parameters of this synthetic model are detailed in Tables 1a 


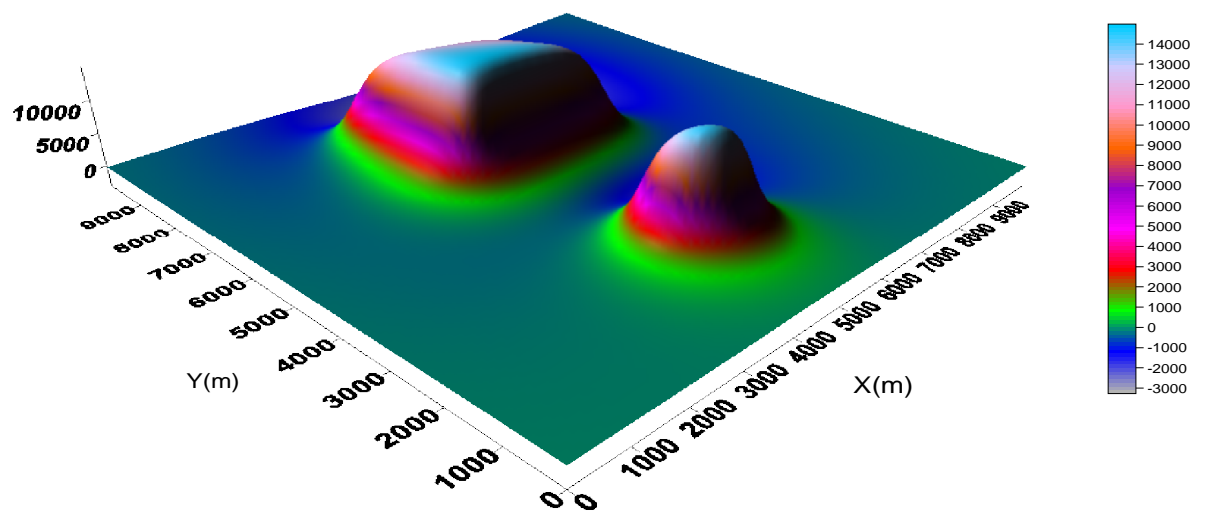

Figure 2a. Synthetic geomagnetic anomaly field of a cylinder and a prism in nT.

Table $1 \mathrm{~b}$. Physical parameters of the prism.

\begin{tabular}{ll}
\hline Coordinates of the center & $(5000,7000,-300)$ \\
\hline Width & $3000 \mathrm{~m}$ \\
Length & $3000 \mathrm{~m}$ \\
High & $2000 \mathrm{~m}$ \\
Magnetic susceptibility & $K=0.01 \mathrm{SI}$ \\
$F$ & $37000 \mathrm{nT}$ \\
Declination & $D=30^{\circ}$ \\
Inclination & $I=60^{\circ}$ \\
\hline
\end{tabular}

and $b$. The anomaly magnetic field of this model is presented in Fig. 2a, data are processed with a regular grid of $150 \mathrm{~m} \times 150 \mathrm{~m}$. One can observe that maximums of magnetic anomaly field are not located at the vertical of each structure. This is due to the inclination and declination effects. Firstly, we have tested the method proposed by Ouadfeul et al. (2012) to delineate structural boundaries in cases of high remanence. This last step is based only to the mapping of maxima of the 2-D directional continuous wavelet transform. The modulus of the 2-D continuous wavelet transform for the smaller scale $a=424 \mathrm{~m}$ is presented in Fig. 2b; the analyzing wavelet is the Poisson kernel defined by Eq. (4). Scales are varying following a power law:

$a_{j}=a_{0} \cdot 2^{j * d j} j=0,1, \ldots \ldots, N$

$a_{0}=2 \cdot \sqrt{(\Delta X)^{2}+(\Delta Y)^{2}}$.

$\Delta X$ is the grid dimension following the $x$ dimension. $\Delta Y$ is the grid dimension following the $y$ dimension.

$N=\frac{1}{d_{j}} \log \left(\frac{\left(\Delta X \cdot N_{\max }\right)^{2}+\left(\Delta Y \cdot M_{\max }\right)^{2}}{a_{0}}\right) / \log (2)$

where $d_{j}$ is a real number, $N_{\max }=67$, and $M_{\max }=67$.

Ouadfeul et al. (2012) showed that the boundaries of structures are delineated by mapping maxima of the CWT for each scale; scales are varied following a power law of two

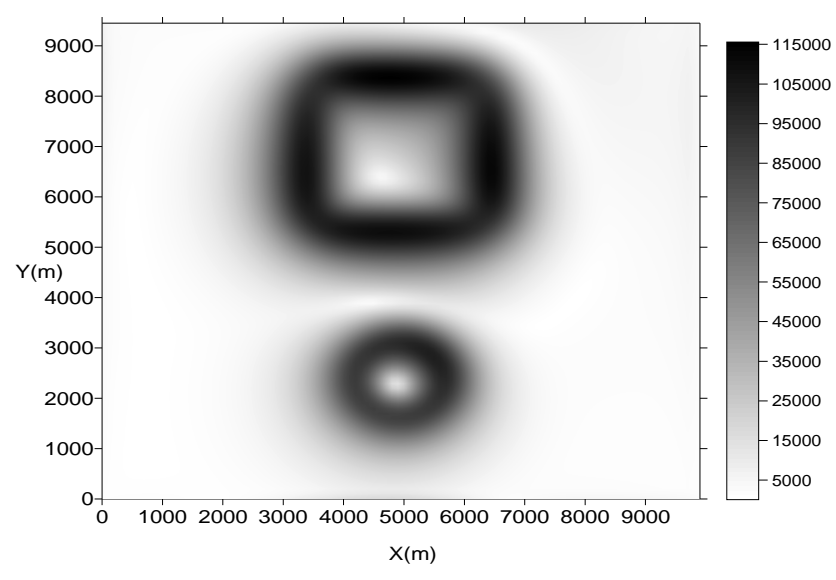

Figure 2b. Modulus of the directional CWT of the synthetic geomagnetic anomaly field.

from 424 to $11818.98 \mathrm{~m}$. Maxima of the CWT are mapped in Fig. 2c. The solid curves are the exact boundaries of these structures. It is clear that the CWT method is not able to delineate boundaries, and requires a reduction to the pole (RTP). The RTP requires the knowledge of the magnetic inclination and declination in areas of high remanence, which always needs petrophysical measurement at the laboratory.

The next step consists in checking the 3-D analytic signal (AS) method proposed by Roest et al. (1992) and the method proposed by Ouadfeul and his collaborators, combined with the AS to delineate structural boundaries in cases of noisy geomagnetic data with high remanence. Figure $3 \mathrm{a}$ is the noisy geomagnetic anomaly with $5 \%$ white noise. Figure $3 \mathrm{~b}$ is the modulus of the CWT at the smaller scale $a=424 \mathrm{~m}$. One can easily observe the signature of the noise in the CWT. Maxima of the CWT are mapped in Fig. 3c; we can observe that the CWT method is affected by noise and it requires a reduction to the pole (RTP) before processing of the anomaly magnetic field.

To test the sensitivity of the analytic signal to the remanence and noise, we have calculated the amplitude of the 


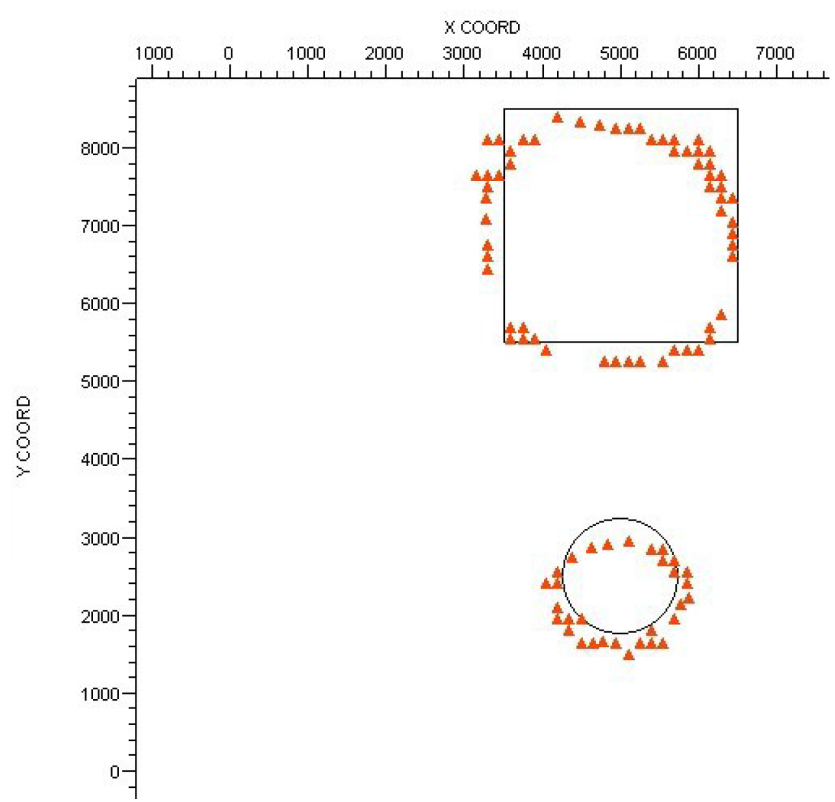

Figure 2c. Obtains contacts by mapping maxima of the CWT. Solid curves are the exact boundaries of the cylinder and the prism.

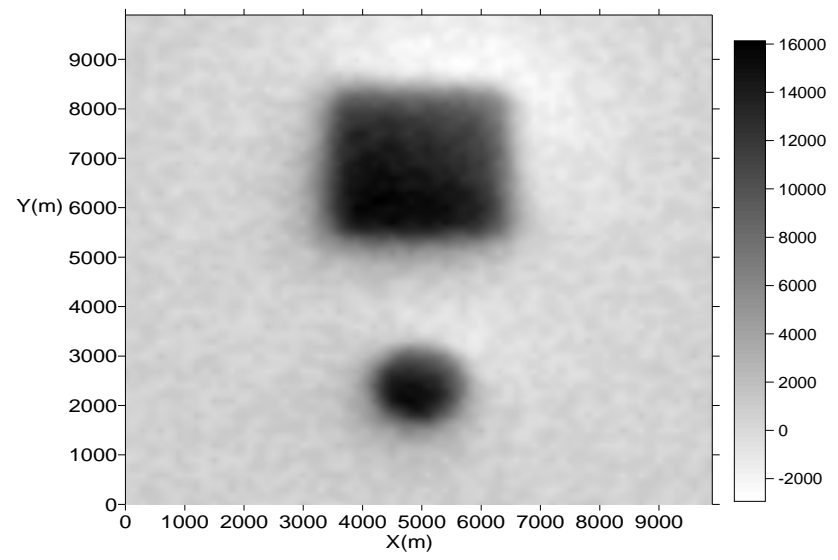

Figure 3a. Noisy synthetic geomagnetic anomaly field in nT.

analytic signal (Fig. 4a) and have mapped maxima of the AS using the Blackly and Simpson method (1986). Maxima of the AS are presented in Fig. 4b. It is clear that the AS is very sensitive to noise. This sensitivity is due to the derivative operator that amplifies noise.

To resolve these ambiguities, we propose in this paper a method based on the combination between the analytic signal and the continuous wavelet transform. To check the robustness of this method on synthetic data, we have applied this technique to the noisy geomagnetic model presented in Fig. 3a. Figure 5a shows the modulus of the CWT of the AS at smaller scale $a=424 \mathrm{~m}$. Maxima of the CWT are mapped in Fig. 5b using the above technique; it is clear that the proposed tool detects with an excellent precision the limits of

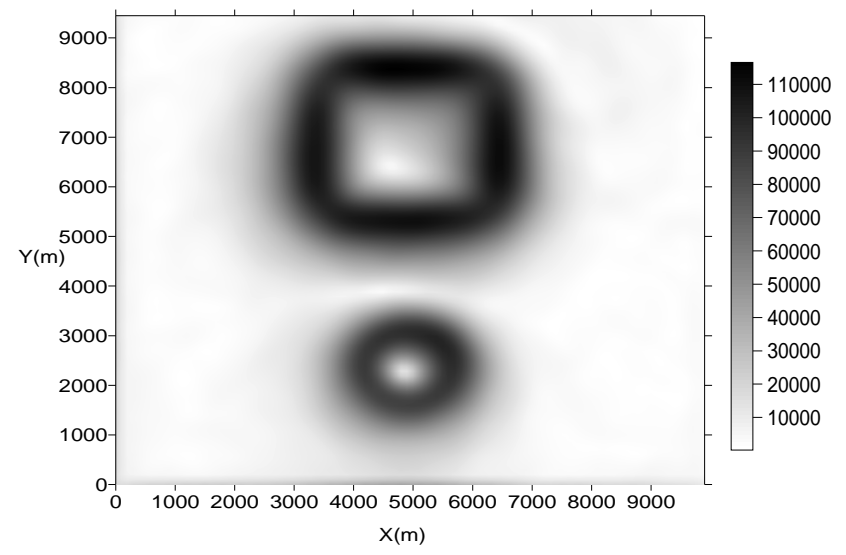

Figure 3b. Modulus of the CWT of the noisy synthetic model at the smaller scale $a=424 \mathrm{~m}$.

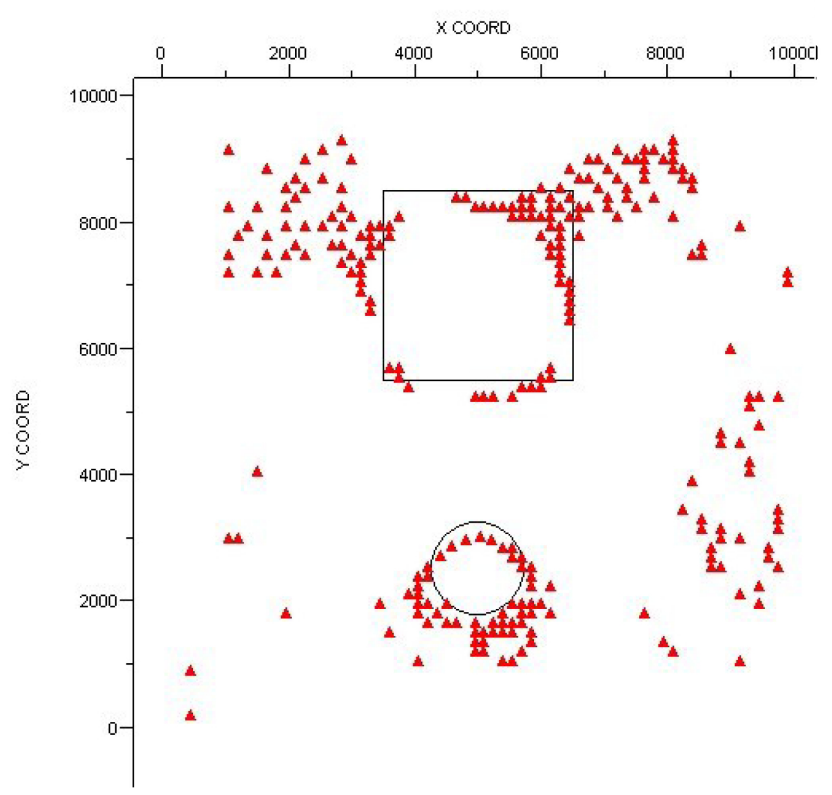

Figure 3c. Obtained boundaries of the modulus of the CWT of the noisy anomaly magnetic field.

the prism and the cylinder. In addition, this technique is not sensitive to noise. This is explained by effect of the CWT on the amplitude of the AS: CWT is a low pass filter which attenuates the high frequency components of the 3-D analytic signal.

\section{Application to real data}

The proposed idea is applied to real aeromagnetic data of an area located on the west part of Hoggar (Algeria). We start with a description of the geology of the massif of Hoggar. 


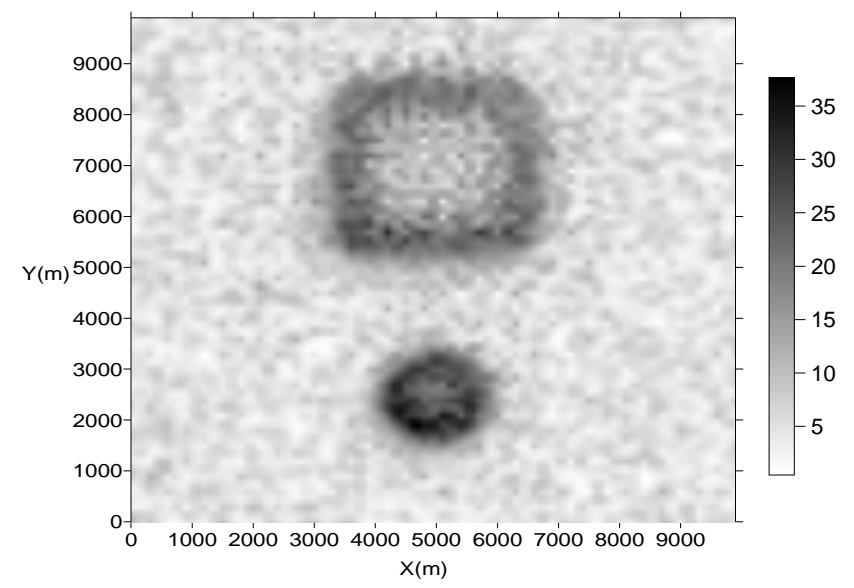

Figure 4a. Amplitude of the 3-D analytic signal of the noisy synthetic model.

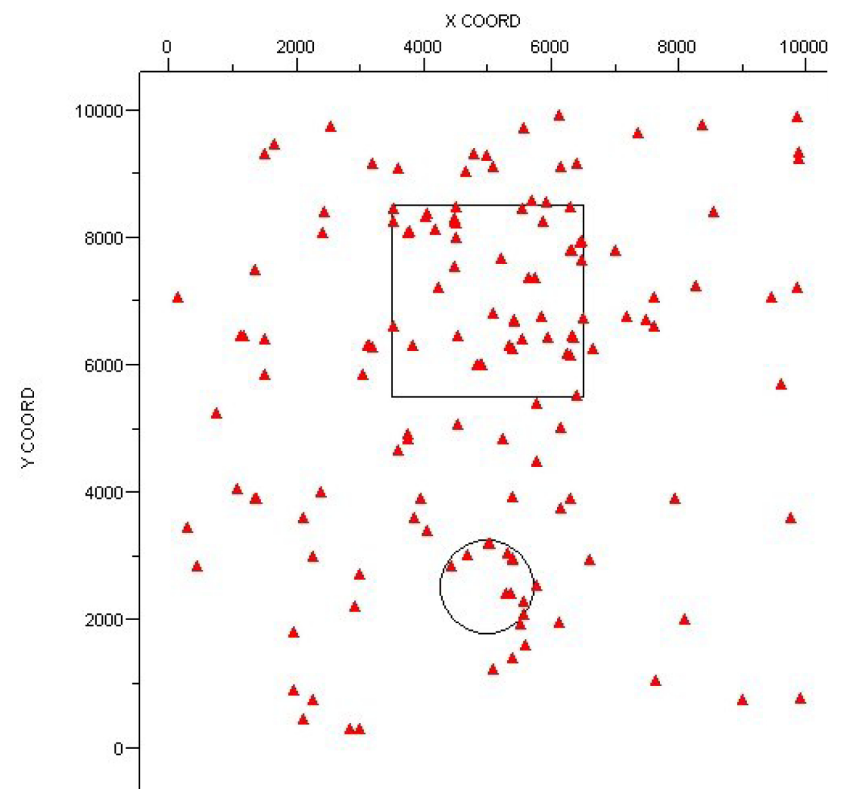

Figure 4b. Obtained contacts by mapping maxima of the amplitude of the AS. Maxima are localized using Blackly and Simpson method (Blakely and Simpson, 1986).

\subsection{Geological setting of Hoggar}

The lens of the massif of Hoggar that occupies the southern part of Algeria (Fig. 6) is defined as a wide lapel Precambrian. It integrates mobile areas caught between the West African Craton and East Africa. It extends $1000 \mathrm{~km}$ from east to west and $700 \mathrm{~km}$ from north to south, extending through the branches "append" of Air-NIGER south-east and the Adrar des Iforas-MALI south-west. Its territory is covered to the north-east and south in part by training Paleozoic sedimentary of Tassili. The entire range (Hoggar, Air and Adrar des Iforas) forms the Tuareg Shield (also known as Tuargi Shield). Stable since the Cambrian, this massif belongs to

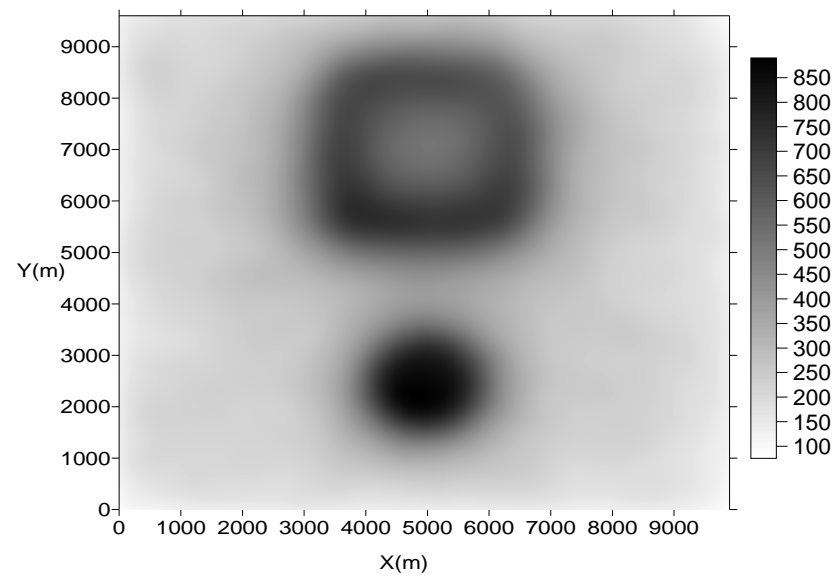

Figure 5a. Modulus of the continuous wavelet transform of the amplitude of the analytic signal at the smaller scale $a=424 \mathrm{~m}$.

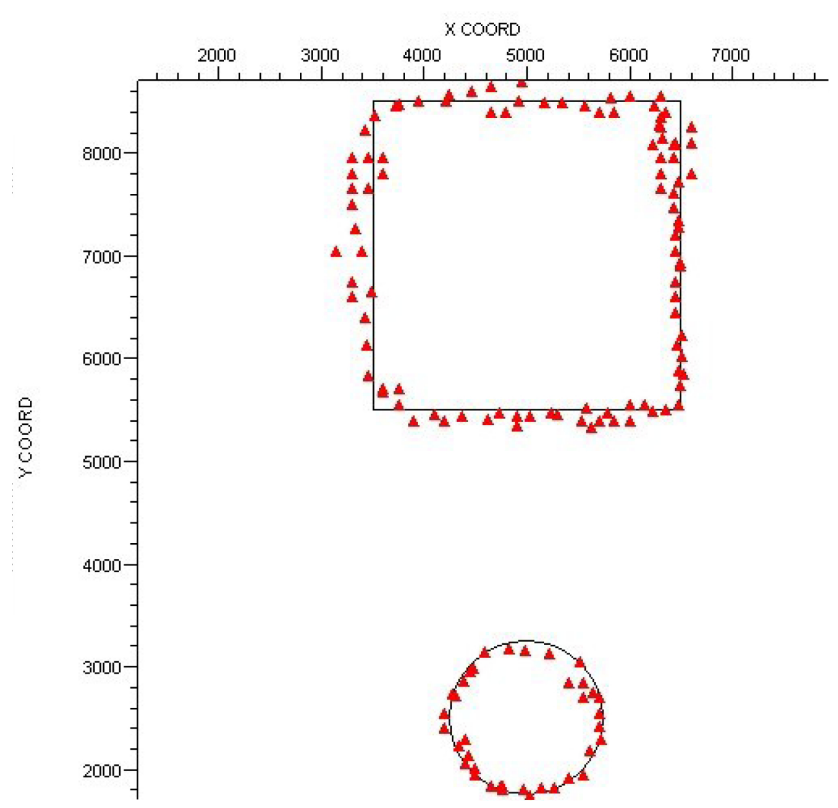

Figure $5 \mathrm{~b}$. Obtained boundaries by mapping maxima of the modulus of the CWT of the amplitude of the AS.

the chain called "Pan", which belts the West African Craton to the east. This old chain is probably the result of the evolution of both intercontinental basins and accretion of micro plates involving the creation of oceans and island arcs. It is surrounded by a sediment platform of the Paleozoic age (Ouadfeul et al., 2010).

\subsection{Geological context of In Ouzzal}

The In Ouzzal terrane (Western Hoggar) is an example of Archaean crust remobilized by a very-high-temperature metamorphism (Ouzeggane and Boumaza, 1996) during the Paleoproterozoic (2Ga). Structural geometry of the In Ouzzal 


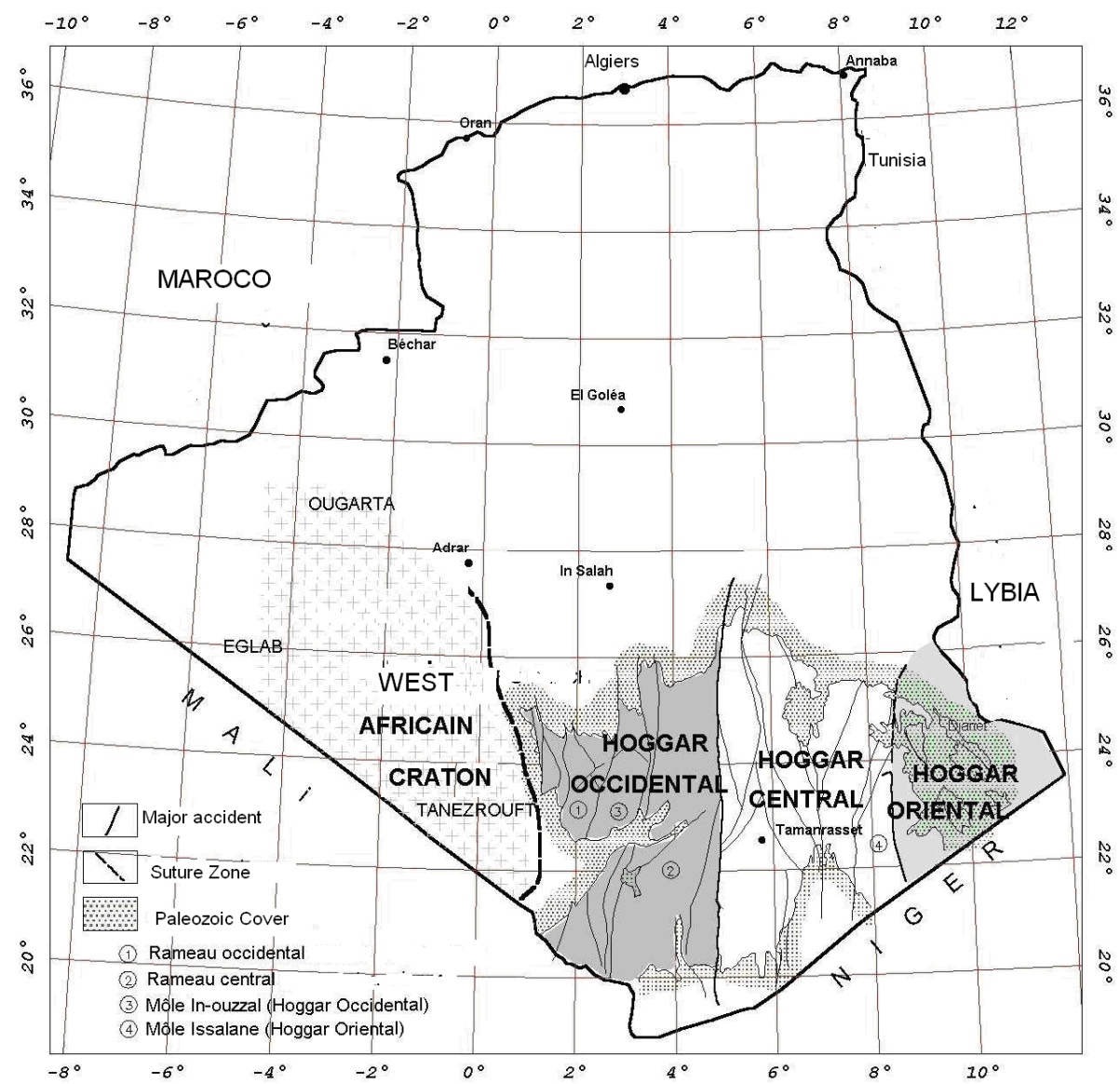

Figure 6. Geographic location of the massif of Hoggar (Algeria).

terrane is characterized by closed structures trending NESW to ENE-WSW (Fig. 7) that correspond to domes of charnockitic orthogneiss. The supracrustal series are made up of metasediments and basic/ultrabasic rocks that occupy the basins located between these domes. In the In Ouzzal area, the supracrustal synforms and orthogneiss domes exhibit linear corridors near their contacts corresponding to shear zones. The structural features in the In Ouzzal area (Djemaï et al., 2009), observed at the level of the base of the crust, argue in favour of a deformation taking place entirely under granulite-facies conditions during the Paleoproterozoic. These features are compatible with $D_{1}$ homogeneous horizontal shortening of overall NW-SE trend that accentuates the vertical stretching and flattening of old structures in the form of basins and domes. This shortening was accommodated by horizontal displacements along transpressive shear corridors. During the Pan-African event, the brittle deformation affected the granulites, which were retrogressed amphibolite and greenschists facies (with the development of tremolite and chlorite, Caby and Monie, 2003), in the presence of fluids along shear zones corridors. Brittle deformations were concentrated in the southern boundary of In Ouzzal. An important NW-SE-trending dextral strike-slip pat- tern has been mapped along which we can see the Eburnean foliation F1 overprinted. This period was also marked by ductile to brittle deformation along the eastern shear zone bordering the In Ouzzal terrane with steep fracture cleavage (NNW-SSE) and conjugate joint pattern. All these structural features are compatible with an ENE-WSW shortening in relation with the collision between the West African Craton and the Hoggar during the Pan-African orogeny.

\subsection{Data processing}

The proposed technique is applied to the aeromagnetic data of In Ouzzal; the data are processed with a regular grid of $750 \mathrm{~m} \times 750 \mathrm{~m}$. Figure 8 shows the total magnetic field. Firstly, the normal magnetic field is removed using the IGRF75 model. Figure 9 presents the anomaly magnetic field. The next operation consists in calculating the amplitude of the analytic signal (see Fig. 10). The modulus of the continuous wavelet transform of the amplitude of the AS at the smaller scale $a=2121 \mathrm{~m}$ is presented in Fig. 11; the analyzing wavelet is the Poisson kernel (Fedi and Cascone, 2008; Ouadfeul et al., 2012). Maxima of the modulus of the CWT are mapped for all range of scales (scales varied from 2121 


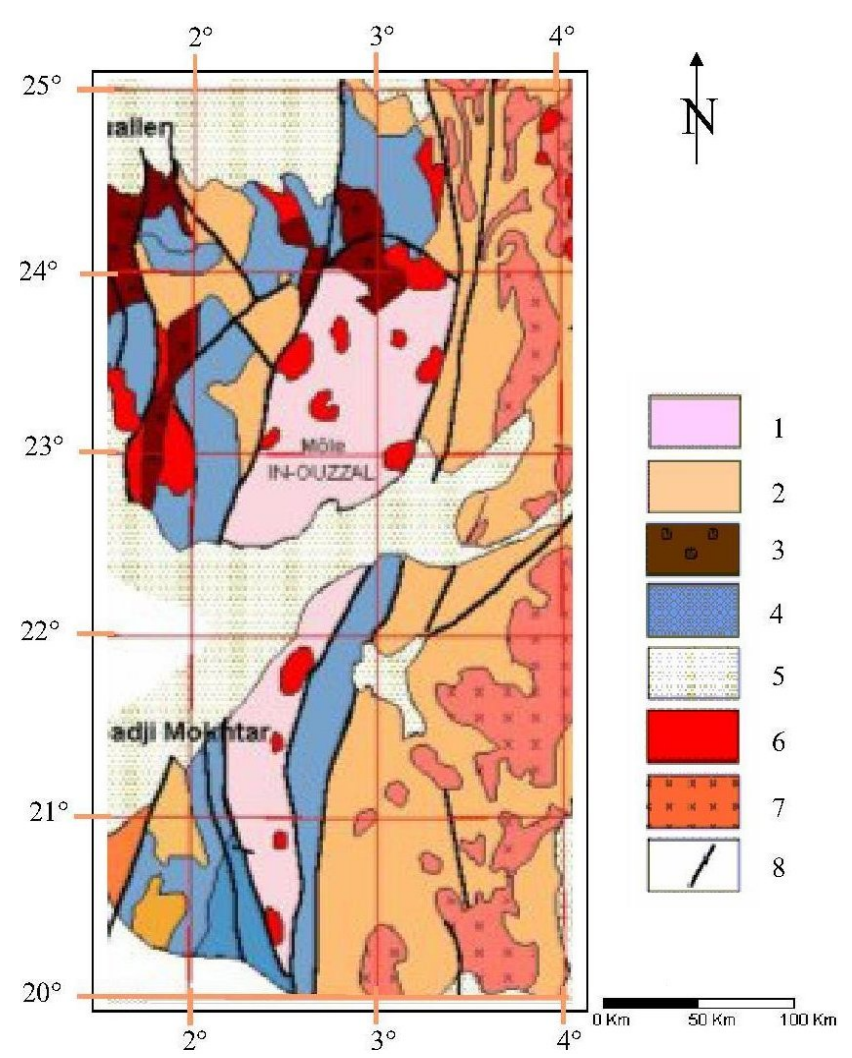

Figure 7. Geological map of the Mole In Ouzzal extracted from the map of Hoggar (after Caby et al., 1981). 1 - Archaean granulites; 2 - Gneiss and metasediments; 3 - Gneiss with facies amphibole; 4 - Indif gneiss; 5 - Paleozoic curvature; 6 - Panafrican granite; 7 Volcanic sediments of Tafassasset; 8 - Major faults.

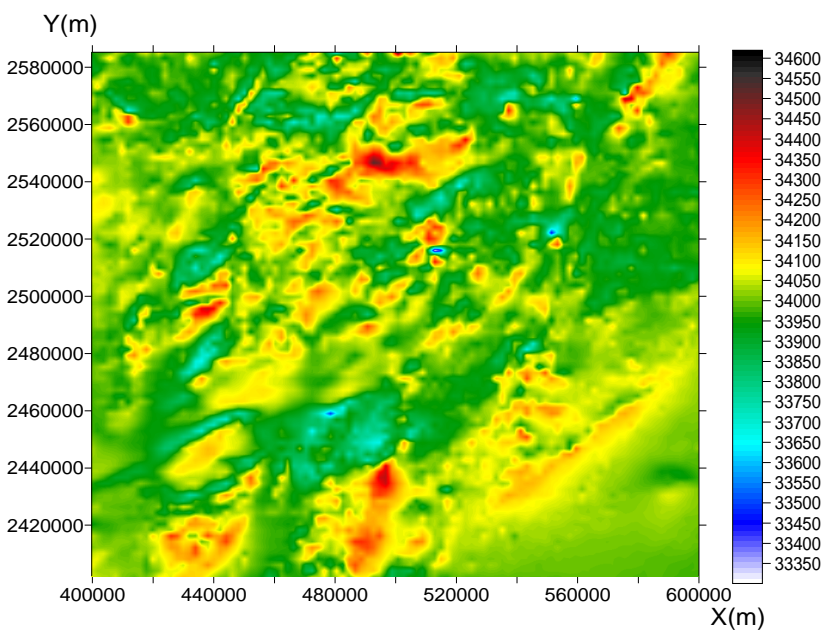

Figure 8. Total magnetic field of In Ouzzal (magnetic field unit is the nT).

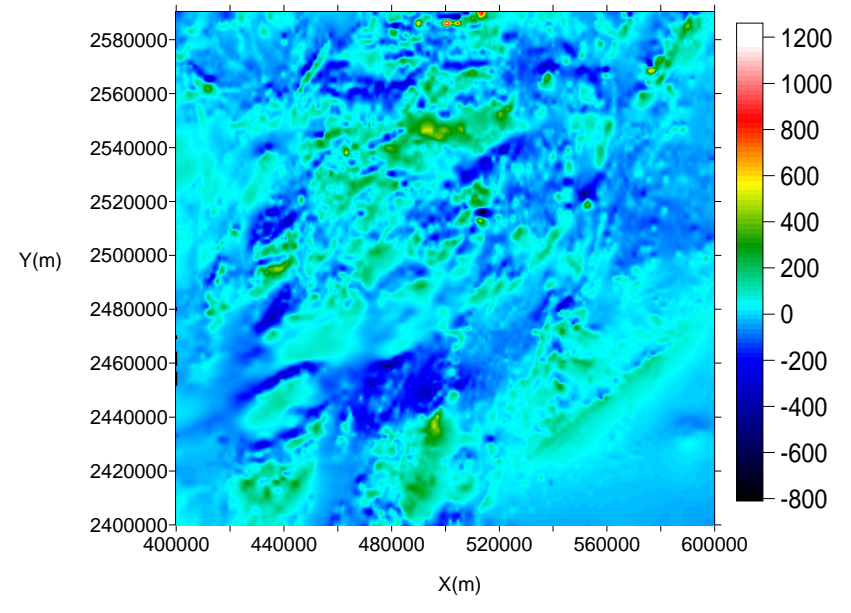

Figure 9. Anomaly magnetic field of In Ouzzal (magnetic field unit is the nT).

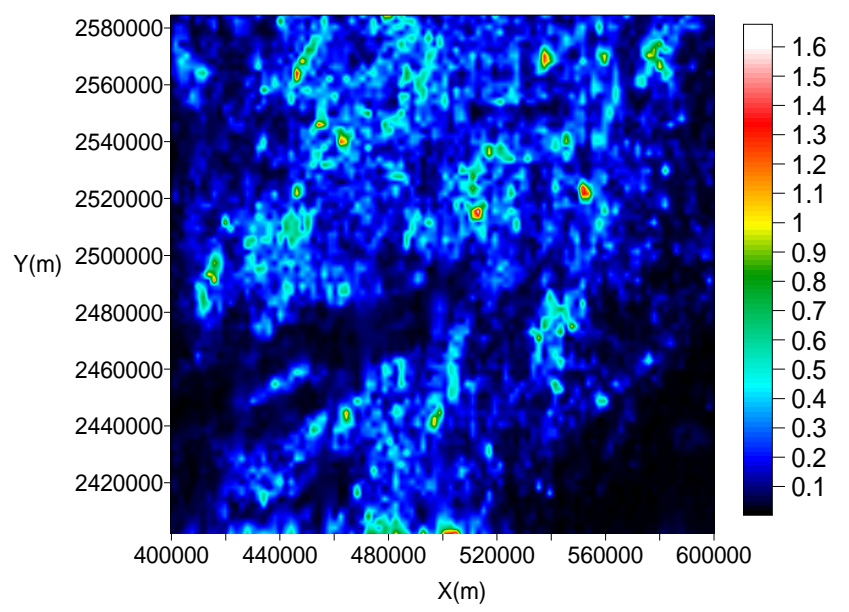

Figure 10. Amplitude of the analytic signal of the anomaly magnetic field of In Ouzzal.

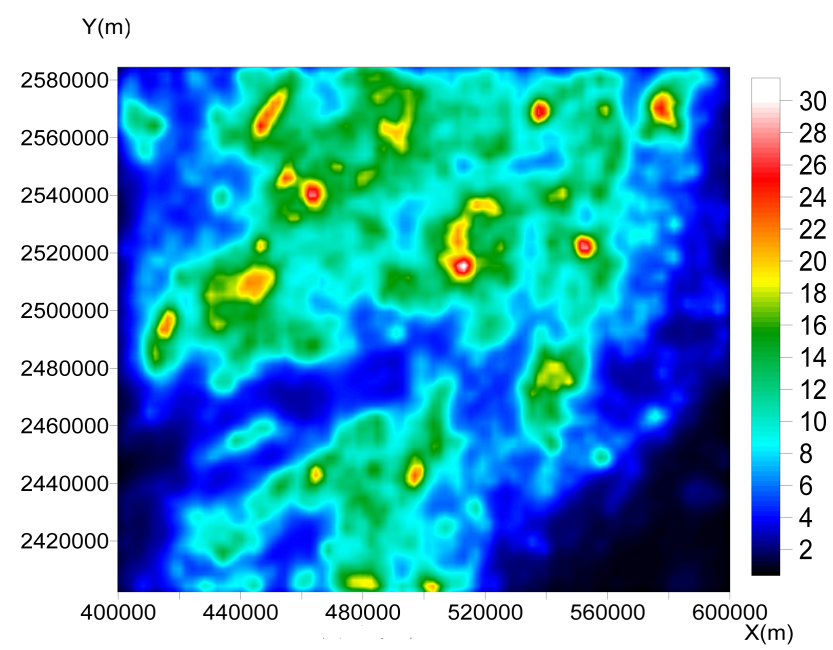

Figure 11. Modulus of the CWT of the AS plotted at the smaller scale $a=2121 \mathrm{~m}$ 


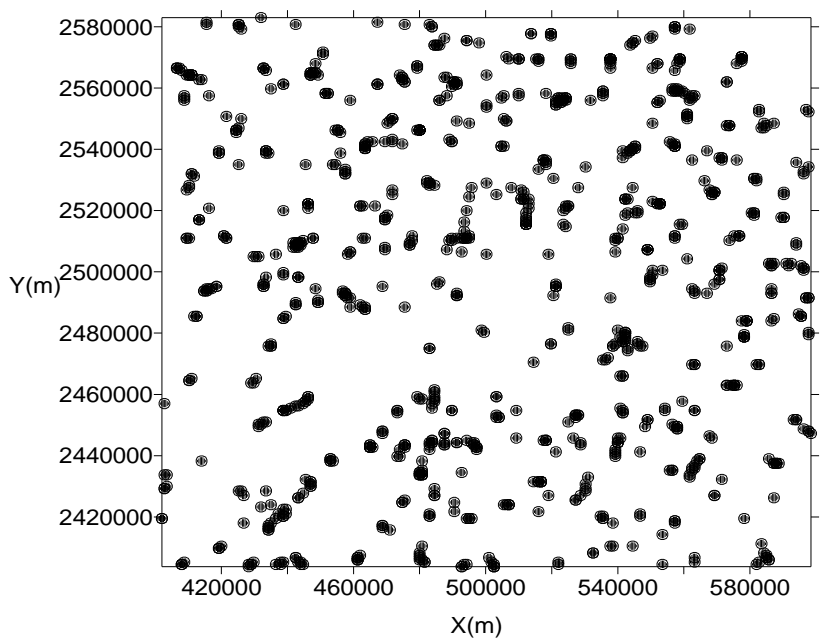

Figure 12. Obtained contacts by the CWT analysis of combined AS.

to $135764.51 \mathrm{~m})$. The set of maxima will provide the pattern of structural boundaries (see Fig. 12).

\subsection{Results interpretation}

Obtained patterns of geological boundaries are compared with the 3-D analytic signal solutions (see Fig. 13); in cases of analytic signal we have reduced the noise effect by applying a threshold of $0.5 \mathrm{nT} \mathrm{m}^{-1}$. Random noise can greatly disturb the AS solutions and provide false information about pattern of boundaries from maxima of analytic signal. Comparisons of the two model of contacts (Fig. 13) shows that by using this threshold we have eliminated the geological boundary that has a NE-SW trend existing in the structural map (defined by the green dashed line in Fig. 13). This boundary is identified by mapping maxima of the modulus of the 2-D continuous wavelet transform of the amplitude of the 3-D analytic signal (proposed method).

\section{Conclusions}

We have proposed a technique of structural boundaries identification based on the mapping of maxima of the modulus of the 2-D continuous wavelet transform of the amplitude of the 3-D analytic signal. An application to synthetic geomagnetic data shows the robustness of the proposed technique to map geological contacts, where the 3-D analytic signal and 2-D directional continuous wavelet transforms fail. Application to the real aeromagnetic data of In Ouzzal area shows that the proposed idea is able to identify a boundary that was not detected by the analytic signal technique. By implanting our method we have resolved the ambiguity of application of a threshold to the maxima of analytic signal, which can eliminate a lot of high frequency causative sources. Secondly, we have resolved the ambiguity of reduction to the pole (RTP)

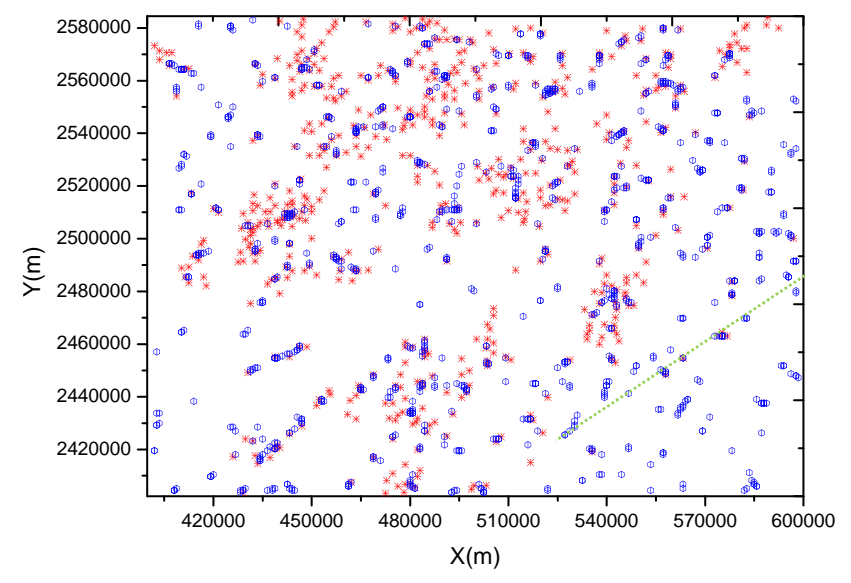

Figure 13. Obtained contacts by the proposed method compared with analytic signal solutions.

that exists in the classical methods of application of the CWT for contacts delimitation. This last step needs data reduced to the pole, which is not very efficient in the case of high geomagnetic remanence. We suggest application of the proposed processing tool to other aeromagnetic data with high remanence to better show more its ability to resolve such sorts of ambiguity.

Acknowledgements. Authors would like to thank the Handling editor and referees for comments that improve the paper.

Edited by: N.-A. Mörner

Reviewed by: two anonymous referees

\section{References}

Ansari, A. H. and Alamdar, K.: Reduction to the Pole of Magnetic Anomalies Using Analytic Signal, World Applied Sciences Journal, 7, 405-409, 2009.

Blakely, R. J. and Simpson, R. W.: Approximating edges of source bodies from magnetic or gravity anomalies, Geophysics, 51, 1494-1498, 1986.

Caby, R. and Monie, P.: Neoproterozoic subduction and differential exhumation of western Hoggar (southwest Algeria): new sructural, petrological and geochronological evidence, J. Afr. Earth Sci., 37, 269-293, doi:10.1016/j.jafrearsci.2003.01.001, 2003.

Caby, R., Bertrand, J. M. L., and Black, R.: Pan-African closure and ontinental collision in the Hoggar-Iforas segment, central Sahara, in: Precambrian Plate Tectonics, edited by: Kroner, A., Elsevier, Amst., 407-434, 1981.

Djemaï, S., Haddoum, H., Ouzegane, K., and Kienast, J.-R.: Archaean Series Reworked At Proterozoic In Amesmessa (West Hoggar): Cartography, Tectonic Evolution And P-T Path, Bulletin du Service Géologique National, 20, 3-29, 2009.

Fedi, M. and Cascone, L.: Continuous wavelet transform of potential field with different choices of analyzing wavelets, 78th SEG Annual Meeting SEG, Expanded Abstracts, 2008. 
Murenzi, R.: Transformée en ondelettes multidimensionnelle et application à l'analyse d'images, Thèse Louvain-La-Neuve, 1989.

Nabighian, M. N.: The analytic signal of two-dimensional magnetic bodies with polygonal cross-section: Its properties and use of automated anomaly interpretation, Geophysics, 37, 507-517, doi:10.1190/1.1440276, 1972.

Nabighian, M. N.: Toward a three-dimensional automatic interpretation of potential field data via generalized Hilbert transforms: Fundamental relations, Geophysics, 49, 957-966, 1984.

Ouzegane, K. and Boumaza, S.: An example of ultra-high temperature metamorphism: orthpyroxene-sillimnite, -garnet, sapphirine-quartz and spinel-quartz parageneses in Al-Mg granulites froum In Hihaou, In Ouzzal, Hoggar, J. Metamorph. Geol., 14, 693-708, 1996.

Ouadfeul, S. and Aliouane, L.: Multiscale analysis of gravity data using the 2D directional continuous wavelet transform, Istanbul 2012 - International Geophysical Conference and Oil \& Gas Exhibition, 2012a.
Ouadfeul, S. and Aliouane, L.: Structural boundaries delimitation from aeromagnetic data using the horizontal gradient and the continuous wavelet transform, Istanbul 2012 - International Geophysical Conference and Oil \& Gas Exhibition, 1-4, 2012b.

Ouadfeul, S., Aliouane, L., and Eladj, S.: Multiscale analysis of gomagnetic data using the continuous wavelet transform, SEG expanded abstract, 29, 1222-1225, doi:10.1190/1.3513065, 2010.

Ouadfeul, S., Hamoudi, M., Aliouane, L., and Eladj, S.: Aeromagnetic data analysis using the directional continuous wavelet transform (DCWT), Arab, J. Geosci., doi:10.1007/s12517-011-04549, 2012.

Roest, W. R., Verhoef, J., and Pilkington, M.: Magnetic interpretation using the 3-D signal analytic, Geophysics, 57, 116-125, 1992. 